\title{
Calcitonin gene-related peptide (CGRP)-induced recovery after myocardial infarction: Is there a role for CGRP-targeted molecular image- guided strategies in cardiology?
}

\author{
Rudolf A. Werner, $M D,{ }^{a, b}$ and Takahiro Higuchi, $M D, P^{a, b, c}$ \\ a Department of Nuclear Medicine, University Hospital Würzburg, Würzburg, Germany \\ b Comprehensive Heart Failure Center, University Hospital Würzburg, Würzburg, Germany \\ c OkayamaUniversity Graduate School of Medicine, Dentistry and Pharmaceutical Sciences, \\ Okayama, Japan
}

Received May 24, 2021; accepted May 24, 2021

doi: $10.1007 / \mathrm{s} 12350-021-02686-8$

\section{See related article, pp. 2090-2099}

As a potential vasodilator, ${ }^{1,2}$ the discovery of the Alpha-Calcitonin Gene-Related Peptide (CGRP) immediately triggered studies to investigate potential cardioprotective effects, e.g., in dilated cardiomyopathy. ${ }^{3}$ Therefore, in the present study, Bentsen et al aimed to investigate the effect on cardiac recovery after administration of a systemically applied alpha-CGRP analogue $(\mathrm{SAX})$ in rats after myocardial infarction (MI). ${ }^{4}$ Relative to placebo-treated controls, the SAX group had improved cardiac defect sizes during longterm follow-up, as assessed by $99 \mathrm{mTc}$-sestamibi SPECT. ${ }^{4}$ Moreover, in rats that died in the subacute phase early after MI, the SAX group demonstrated a significant longer survival time relative to placebo. ${ }^{4}$ The authors concluded that in rats, SAX has a cardio-beneficial effect after permanent coronary occlusion. ${ }^{4}$ The present study provides not only insights in SAX-related beneficial long-term outcome in animals after MI but also on prolonged survival in a subacute phase early after the acute event. In this regard, the authors extended

Funding A KAKENHI grant (JP15K21774) has been provided for Dr. T. Higuchi from the Japan Society for the Promotion of Science (JSPS).

Reprint requests: Rudolf A. Werner, MD, Department of Nuclear Medicine, University Hospital Würzburg, Oberdürrbacherstr. 6, 97080 Würzburg, Germany; rudolfwerner2015@gmail.com

J Nucl Cardiol 2022;29:2100-2.

$1071-3581 / \$ 34.00$

Copyright (c) 2021 The Author(s) the current knowledge on CGRP treatment in the context of myocardial ischemia in vivo. ${ }^{4,5}$ Källner was among the first to prove that exogenously administered CGRP can improve post-ischemic coronary flow early after MI, but the authors could not provide evidence on a cardioprotective effect of CGRP during long-term followup. ${ }^{5}$ The authors of the present study, however, used SPECT as an endpoint to assess infarct size three weeks after the acute event, demonstrating smaller perfusion defects, thereby suggesting that SAX can also improve long-term cardiac outcome. ${ }^{4}$ However, to further provide more evidence whether SAX treatment would be indeed useful to improve cardiac performance in a chronic phase post-MI, future studies should use combined multimode endpoints to provide more functional information, e.g., by also implementing cardiac magnetic resonance $(\mathrm{MR}$, including ventricular volumes or ejection fraction) ${ }^{6}$ or using PET perfusion radiotracers, such as ${ }^{18} \mathrm{~F}$-flurpiridaz providing more details on the extent of local ischemia. ${ }^{7,8}$

Bentsen et al decided for a permanent coronary occlusion model, as this may lead to an increased defect size and severity of local ischemia in the present proofof-concept study. ${ }^{4,9}$ Future studies, however, may also investigate a dedicated coronary occlusion-reperfusion model closely mimicking the setting of percutaneous coronary intervention in patients, which may be also more clinically relevant. ${ }^{9}$ Such future studies may then also correlate the infarct size (e.g., assessed by SPECT) to immunohistochemistry, e.g., using triphenyl tetrazolium chloride or by assessing associations with CGRP plasma levels. 5

Moreover, beyond using SPECT for the assessment of infarct size as a potential endpoint, it would be also 
interesting to use the recently introduced CGRP-targeted PET radiotracer $11 \mathrm{C}-\mathrm{MK}-4232$ in the present study setting. ${ }^{10}$ For instance, 11C-MK-4232 could be applied to SAX-treated animals vs placebo. ${ }^{4,10}$ Such an approach would allow to assess the retention capacities of SAX or other CGRP / vasodilating analogues prior to treatment on-set. ${ }^{11}$ For instance, a CGRP-related treatment could then be initiated at an increased 11C-MK4232 radiotracer signal and compared to off-peak-treated animals post-MI, i.e., when the image biomarker signal has been dissipated. ${ }^{12}$ Such an elaborated approach of a molecular image-guided treatment strategy has been recently evaluated by targeting the C-X-C motif chemokine receptor 4 using the PET image agent 68Ga-Pentixafor in mice after MI, demonstrating that CXCR4 inhibition at the maximum of the target expression has a beneficial outcome when compared to off-peak-treated animals. ${ }^{13}$ To date, it remains unclear whether such an image-guided strategy may also work for targeting CGRP using PET technology. First in-human studies, however, reported on a high safety profile of $11 \mathrm{C}-\mathrm{MK}-4232$, and these encouraging results may trigger future studies in patients post-MI using this CGRP-targeting image agent, preferably in a translational set-up. ${ }^{14}$ In this regard, the short half-life of C11 (20 min) would make a clinical use rather challenging, and therefore, F18-labeled CGRP-directed radiotracers (half-life, $110 \mathrm{~min}$ ) would be needed. ${ }^{15}$ Nonetheless, the present work of Bentsen et al lays the groundwork for future studies investigating the concept of image-guided treatment strategies post-MI, e.g., in a preclinical model after transient coronary occlusion randomizing animals to an on-peak group (treated at the maximum of the $11 \mathrm{C}-\mathrm{MK}-4232$ signal in the infarct) vs an off-peak group. ${ }^{13}$ Moreover, CGRP has been also advocated to play a potential role in cardiorenal interactions. For instance, it has been shown that deletion of the CGRP gene causes hypertension-induced end organ damage in both the heart and kidneys. ${ }^{16}$ As such, after primary cardiac damage, potential benefits for renal endpoints after CGRP treatment could be also assessed, ${ }^{12,17}$ e.g., by implementing additional kidney MR to investigate improvement in renal perfusion due to SAX-caused vasodilatation in the kidneys. ${ }^{18}$

\section{Disclosure}

The authors declare that they have no conflict of interest.

\section{Funding} DEAL.

Open Access funding enabled and organized by Projekt

Open Access This article is licensed under a Creative Commons Attribution 4.0 International License, which permits use, sharing, adaptation, distribution and reproduction in any medium or format, as long as you give appropriate credit to the original author(s) and the source, provide a link to the Creative Commons licence, and indicate if changes were made. The images or other third party material in this article are included in the article's Creative Commons licence, unless indicated otherwise in a credit line to the material. If material is not included in the article's Creative Commons licence and your intended use is not permitted by statutory regulation or exceeds the permitted use, you will need to obtain permission directly from the copyright holder. To view a copy of this licence, visit http://creativecommo ns.org/licenses/by/4.0/.

\section{References}

1. Russell FA, King R, Smillie SJ, Kodji X, Brain SD. Calcitonin gene-related peptide: physiology and pathophysiology. Physiol Rev 2014;94:1099-142.

2. Brain SD, Williams TJ, Tippins JR, Morris HR, MacIntyre I. Calcitonin gene-related peptide is a potent vasodilator. Nature 1985;313:54-6.

3. Dubois-Rande JL, Merlet P, Benvenuti C, Sediame S, MacquinMavier I, Chabrier E, et al. Effects of calcitonin gene-related peptide on cardiac contractility, coronary hemodynamics and myocardial energetics in idiopathic dilated cardiomyopathy. Am J Cardiol 1992;70:906-12.

4. Bentsen S, Sams A, Hasbak P, Edvinsson L, Kjaer A, Ripa RS. Myocardial perfusion recovery induced by an $\alpha$-calcitonin generelated peptide analogue. J Nucl Cardiol 2021.

5. Kallner G, Gonon A, Franco-Cereceda A. Calcitonin gene-related peptide in myocardial ischaemia and reperfusion in the pig. Cardiovasc Res 1998;38:493-9.

6. Thackeray JT, Hupe HC, Wang Y, Bankstahl JP, Berding G, Ross $\mathrm{TL}$, et al. Myocardial inflammation predicts remodeling and neuroinflammation after myocardial infarction. J Am Coll Cardiol 2018;71:263-75.

7. Werner RA, Chen X, Rowe SP, Lapa C, Javadi MS, Higuchi T. Moving into the next era of PET myocardial perfusion imaging: introduction of novel (18)F-labeled tracers. Int J Cardiovasc Imaging 2019;35:569-77.

8. Werner RA, Koshino K, Arimitsu K, Lapa C, Javadi MS, Rowe SP, et al. Stability of distribution of F18 flurpiridaz after transient coronary occlusion in pigs. JACC Cardiovasc Imaging 2019;12:2269-71.

9. Chen T, Vunjak-Novakovic G. In vitro models of ischemiareperfusion injury. Regen Eng Transl Med 2018;4:142-53.

10. Bell IM, Gallicchio SN, Stump CA, Bruno JG, Fan H, Gantert LT, et al. [(11)C]MK-4232: The first positron emission tomography tracer for the calcitonin gene-related peptide receptor. ACS Med Chem Lett 2013;4:863-8. 
11. Zhu J, Pedersen MD, Ahmed LS, Abdolalizadeh B, Grell AS, Berg JO et al. Fluorescent analogues of human alpha-calcitonin generelated peptide with potent vasodilator activity. Int J Mol Sci 2020;21

12. Werner RA, Thackeray JT, Diekmann J, Weiberg D, Bauersachs J, Bengel FM. The changing face of nuclear cardiology: guiding cardiovascular care toward molecular medicine. J Nucl Med 2020;61:951-61.

13. Hess A, Derlin T, Koenig T, Diekmann J, Wittneben A, Wang Y, et al. Molecular imaging-guided repair after acute myocardial infarction by targeting the chemokine receptor CXCR4. Eur Heart J 2020;41:3564-75.

14. Hostetler ED, Joshi AD, Sanabria-Bohorquez S, Fan H, Zeng Z, Purcell $\mathrm{M}$, et al. In vivo quantification of calcitonin gene-related peptide receptor occupancy by telcagepant in rhesus monkey and human brain using the positron emission tomography tracer [11C]MK-4232. J Pharmacol Exp Ther 2013;347:478-86.

15. Werner RA, Chen X, Rowe SP, Lapa C, Javadi MS, Higuchi T. Recent paradigm shifts in molecular cardiac imaging-Establishing precision cardiology through novel (18)F-labeled PET radiotracers. Trends Cardiovasc Med 2020;30:11-9.

16. Supowit SC, Rao A, Bowers MC, Zhao H, Fink G, Steficek B, et al. Calcitonin gene-related peptide protects against hypertension-induced heart and kidney damage. Hypertension 2005;45:109-14.

17. Werner RA, Hess A, Koenig T, Diekmann J, Derlin T, Melk A, et al. Molecular imaging of inflammation crosstalk along the cardio-renal axis following acute myocardial infarction. Theranostics 2021. https://doi.org/10.7150/thno.61423.

18. Nery F, Buchanan CE, Harteveld AA, Odudu A, Bane O, Cox EF, et al. Consensus-based technical recommendations for clinical translation of renal ASL MRI. MAGMA 2020;33:141-61.

Publisher's Note Springer Nature remains neutral with regard to jurisdictional claims in published maps and institutional affiliations. 